\title{
Cyclin A1 regulates WT1 expression in acute myeloid leukemia cells
}

\author{
UTZ KRUG $^{1 *}$, AMBER YASMEEN $^{1 *}$, CARMELA BEGER $^{3}$, NICOLE BÄUMER $^{1}$, \\ MARTIN DUGAS ${ }^{2}$, WOLFGANG E. BERDEL ${ }^{1}$ and CARSTEN MÜLLER-TIDOW ${ }^{1}$ \\ Departments of ${ }^{1}$ Medicine, Hematology and Oncology, ${ }^{2}$ Medical Informatics and Biomathematics, \\ and the Interdisciplinary Center of Clinical Research, University Hospital of Münster, \\ Albert-Schweitzer-Str. 33, 48129 Münster; ${ }^{3}$ Department of Cellular and Molecular \\ Pathology, Hannover Medical School, Carl-Neuberg-Str. 1, 30625 Hannover, Germany
}

Received April 2, 2008; Accepted June 12, 2008

DOI: 10.3892/ijo_00000136

\begin{abstract}
Cyclin A1 is a cell cycle protein that is expressed in testes, brain and CD34-positive hematopoietic progenitor cells. Cyclin A1 is overexpressed in a variety of myeloid leukemic cell lines and in myeloid leukemic blasts. Transgenic cyclin A1 overexpressing mice develop acute myeloid leukemia with low frequency. In this study, we looked for putative target genes of cyclin A1 in hematopoietic cells. Microarray analysis of U937 myeloid cells overexpressing cyclin A1 versus conrol cells detected 35 differential expressed genes, 21 induced and 14 repressed ones upon cyclin A1 overexpression. Among the differentially expressed genes WT1 was chosen for further analysis. Repression of WT1 expression was confirmed on the mRNA and protein level. In addition, WT1 expression was higher in bone marrow, liver and ovary of cyclin $\mathrm{A}^{-/}$mice. Isoform analysis showed a profound change of the WT1 isoform ratio in U937 cyclin A1overexpressing versus control cells. Functional analysis revealed an inhibition of colony growth when WT1 isoforms were transfected into U937 cells, which was not affected by the overexpression of cyclin A1. In addition, overexpression of the WT1 ${ }^{-1+}$ isoform induced a G1 cell cycle arrest which was abrogated upon cotransfection with cyclin A1. This study identified WT1 as a repressed target of cyclin A1 and suggests that the suppression of WT1 in cyclin A1-overexpressing leukemias might play a role in the growth and suppression of apoptosis in these leukemic cells.
\end{abstract}

Correspondence to: Dr Carsten Müller-Tidow, Department of Medicine A, Hematology and Oncology, University of Münster, Domagkstr. 3, 48129 Münster, Germany

E-mail: muellerc@uni-muenster.de

${ }^{*}$ Contributed equally

Key words: cyclin A1, WT1, isoforms, acute myeloid leukemia

\section{Introduction}

Cyclin A1 is a cell cycle protein whose high level expression in human normal tissues is restricted to testes and brain $(1,2)$. Like other cyclins, cyclin A1 shows an oscillating expression during the cell cycle and interacts with cyclin-dependent kinases (CDK's). In case of cyclin A1, it shows a predominant expression in the $\mathrm{S}$ and $\mathrm{G} 2$ phase of the cell cycle and interacts with CDK1 and $2(1,2)$. As a result, downstream targets of the cyclin A1/CDK complexes are activated, including the retinoblastoma $(\mathrm{Rb})$ protein, $\mathrm{E} 2 \mathrm{~F}$ transcription factors (3) and b-myb (4), resulting in cell cycle progression through the $S$ to G2 checkpoint. Male cyclin A $1^{-/-}$mice display a defect in spermatogenesis before the first meiotic cell division (5), suggesting a role for cyclin A1 in spermatogenesis. Apart from this defect, both male and female cyclin $\mathrm{A} 1^{-/-}$mice develop normally.

Additional to testis and brain, cyclin A1 expression can be detected in CD34-positive hematopoietic progenitor cells, and cyclin A1 is overexpressed in a variety of myeloid leukemia cell lines and acute myeloid leukemic blasts of patients $(1,6)$. In addition, transgenic mice overexpressing cyclin A1 display abnormal myelopoiesis and develop acute myeloid leukemia at a low frequency (7). These results suggest a possible role of the overexpression of cyclin A1 in acute myeloid leukemia, but most of the putative target genes of cyclin A1 are still unknown. Herein, we analyzed mRNA expression profiles of leukemic cells overexpressing cyclin A1.

\section{Materials and methods}

RNA extraction and hybridization. Total RNA was extracted from cells using TRIzol reagent (Invitrogen). Total RNA $(10 \mu \mathrm{g})$ was reverse transcribed into cDNA using an oligo-d (T)-T7-primer. Subsequently, T7 polymerase was used for in vitro transcription. During transcription, cRNA was labelled using biotinylated oligonucleotides. The resulting labelled cRNAs were fragmented and hybridized to U95A oligonucleotide microarrays, containing probes for $\sim 12000$ independent transcripts (Affymetrix, Santa Clara, CA). 
Arrays were scanned following staining with streptavidinphycoerythrin, signal amplification with biotinylated antistreptavidin antibodies and subsequent staining with streptavidin-phycoerythrin. Raw data were normalized and scaled to an average level of 2500 .

Analyses of microarray data and bioinformatics. Bioinformatical analyses were performed using Gene spring analysis software (Gene spring). A two-class procedure of the Significance Analysis of Microarrays software (Stanford) was used to identify differentially regulated genes (8). The delta value was set at 0.59. SPSS (SPSS Inc.) was used to evaluate the statistical significance of gene expression differences.

A gene was classified induced or repressed only if its expression level was increased at least 3 -fold or decreased at least 2-fold respectively, in each sample in U937 cells overexpressing cyclin A1 compared to U937-control vector transfected cells with all 3 different FCS concentration samples. In addition, its absolute expression value had to be $>150$ units (Affymetrix average intensity).

Quantitative real-time $R T-P C R$. Total RNA was isolated using TRIzol (Invitrogen) according to the manufacturer's recommendations from U937 cell line. For RT-PCR, RNA was reverse transcribed using M-MLV (Moloney murine leukaemia virus) reverse transcriptase (Promega).

RNA $(1 \mu \mathrm{g})$ was incubated with $1 \mu \mathrm{l}$ RNAse out, in DEPC- $\mathrm{H}_{2} \mathrm{O}$ (RNAse free water) at a total volume of $17.5 \mu \mathrm{l}$ for $5 \mathrm{~min}$ at $70^{\circ} \mathrm{C}$. RNA samples were incubated for $5 \mathrm{~min}$ on ice and again for $10 \mathrm{~min}$ at room temperature. M-MLV $(1 \mu \mathrm{l})$ was added with $5 \mu 1$ of $5 \mathrm{X}$ buffer, $1.25 \mu 1$ of dNTP's and incubated for $1 \mathrm{~h}$ at $42^{\circ} \mathrm{C}$. After reverse transcription MMLV was inactivated by $70^{\circ} \mathrm{C}$ for $15 \mathrm{~min}$. The cDNA samples were diluted to $100 \mu \mathrm{l}$ and $2.5 \mu \mathrm{l}$ of cDNA were used for each PCR reaction. PCR-amplification of the housekeeping gene glyceraldehydes-3-phosphate-dehydrogenase (GAPDH) was used to confirm the quality of cDNA and standardize the total amount of cDNA between different samples. The quantification of mRNA expression levels was carried out using a real-time fluorescence detection method based on TaqMan Instrument (PE Bio systems) (9). The PCR reactions were prepared with 2X master mix (Applied Biosystems, CA, USA) $12.5 \mu 1$, forward and reverse primer $(10 \mu \mathrm{m}) 0.125 \mu \mathrm{l}$ each, probe $(5 \mu \mathrm{m}) 0.5 \mu \mathrm{l}$ and $\mathrm{ddH}_{2} \mathrm{O} 6.75 \mu \mathrm{l}$. Cycling conditions were $50^{\circ} \mathrm{C}$ for $5 \mathrm{~min}, 95^{\circ} \mathrm{C}$ for $2 \mathrm{~min}$, and 40 cycles of $95^{\circ} \mathrm{C}$ for $2 \mathrm{~min}$, and $60^{\circ} \mathrm{C}$ for $2 \mathrm{~min}$. The probes were labelled at the 5 end with the fluorescent dye FAM (WT1) or VIC (GAPDH) and at the 3' end with quencher TAMRA. Relative gene expression levels were calculated using standard curves generated by serial dilutions of U937 cDNA. The relative amounts of gene expression were calculated by using the expression of GAPDH as an internal standard. At least 3 independent analyses were performed for each sample and each gene.

Cell lines and transfection. 32D cells were purchased from DSMZ (Braunschweig, Germany). In this study, 2 stable myeloid leukamia cell lines derived from U937 cells (human myeloid leukemia) were used. U937 cells were transfected

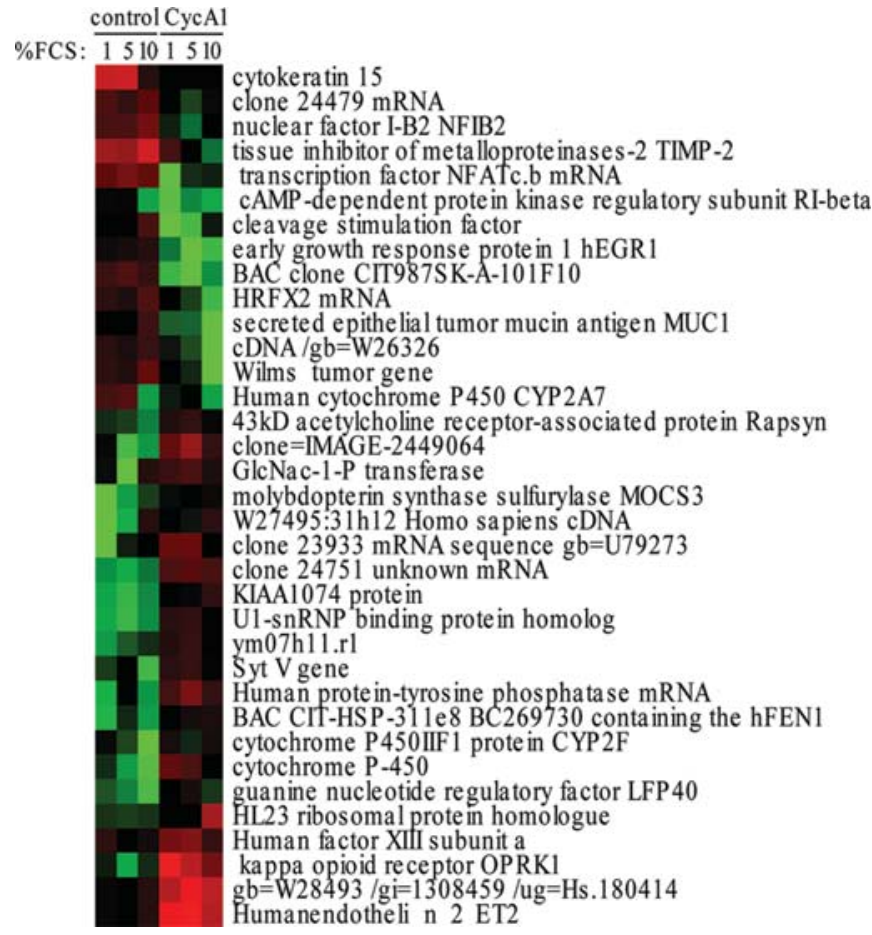

Figure 1. Heatmap of of cyclin A1 overexpression associated transcriptional changes. Oligonucleotide microarray analyses were performed using U95A arrays that contain about 12,500 independent genes. Genes that were differentially expressed between U937-vector control and U937-Cyclin A1 cells were identified using SAM-Analysis and selection criteria based on the strength of induction. For details see text. Hierarchical cluster analysis was performed with differentially expressed genes and clusters were visualized using the Cluster and Tree software (Stanford).

with empty retroviral vector pLXSN as a control cell line or with pLXSN cyclin A1 mRNA (U937 overexpressing cyclin A1). Suspension cell lines were grown in RPMI-1640 medium (Invitrogen), and adherent lines were maintained in Dulbecco's modified Eagle's medium (DMEM, Invitrogen), each supplemented with $2 \mathrm{mM}$ L-glutamine and $10 \%$ FCS (Biochrom KG), $100 \mathrm{U} / \mathrm{ml}$ pencillin and $100 \mu \mathrm{g} / \mathrm{ml}$ streptomycin (Biochrom KG), and $2 \mathrm{mM}$ L-glutamine (Biochrom KG). For 32D cells, the RPMI-1640 medium was additionally supplemented with $20 \mathrm{mM}$ HEPES (Invitrogen). The mammalian cells were grown at $37^{\circ} \mathrm{C}$ and $5 \% \mathrm{CO}_{2}$. The U937 and $32 \mathrm{D}$ cells were transfected following the Amaxa kit (Biosystems) protocol. A total of $5 \mu \mathrm{g}$ of plasmid DNA with $100 \mu 1$ of solution $\mathrm{R}$ per transfection was used. The cells were electroporated by Amaxa program T24, which was optimized for $32 \mathrm{D}$ cells.

Antibodies and Western blotting. Cells were lysed in radioimmunoprecipitation buffer (RIPA) (150 mM NaCl, $1.0 \%$ NP-40, 0.5\% deoxycholic acid (DOC), 0.1\% SDS, $50 \mathrm{mM}$ Tris- $\mathrm{Cl}$ ( $\mathrm{pH}$ 8.0) with complete EDTA-free protease inhibitor). The proteins were run on SDS-PAGE gradient gels (7-14\% Bio-Rad). Proteins sample were electroblotted onto PVDF membranes Immobilon-P (Millipore), probed with specific primary antibodies WT1 (F-6) from Santa Cruz Biotechnology and $B$-actin (Sigma) followed by a secondary antibody against rabbit and mouse IgG antibody conjugated with peroxidase (Jackson ImmunoResearch). Detection was performed with 


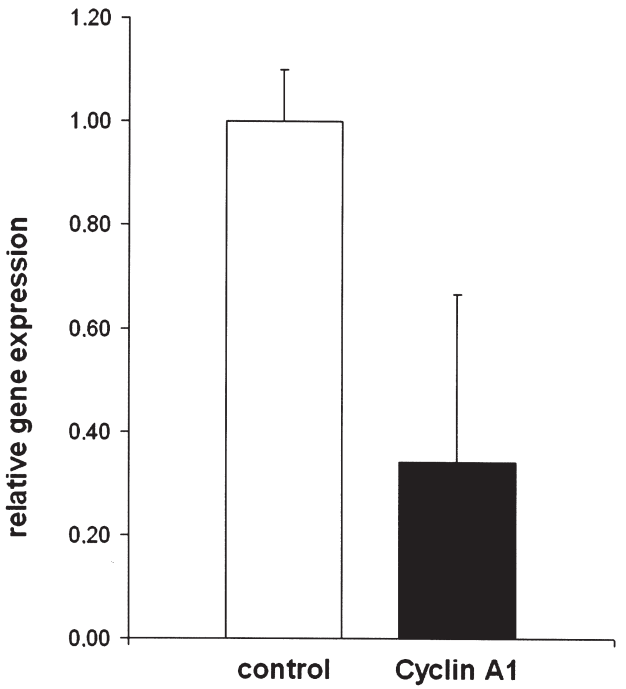

Figure 2. WT1 is downregulated in U937 overexpressing cyclin A1 cells as compared to U937 control cells. Total RNA of U937 control and overexpressing cyclin A1 cells was used in quantative RT-PCR analysis to determine WT1 expression relative to their GAPDH expression.

ECL plus (Amersham Biosciences) and exposure to a radiographic film.

Colony assay. U937 control and overexpressing cyclin A1 or 32D cells were electroporated with $10 \mu \mathrm{g}$ of each pcDNA3, pcDNA3-cyclin A1, pCMV-WT1 ${ }^{+/}$, pCMV-WT1 ${ }^{-/+}$, pCMV$\mathrm{WT}^{-/-}$and $\mathrm{pCMV}-\mathrm{WT} 1^{+/+}$expression vectors (WT1 isoforms were a gift from Dr Jerry Peteiller). After $16 \mathrm{~h}$, cells were separated by gradient centrifuge and $1 \times 10^{5}$ living cells per 35-mm dish were cultured with methylcellulose mix. The methylcellulose mix contained Iscove's modified Dulbecco's medium (IMDM, Invitrogen) with 1\% methylcellulose, $20 \%$ FCS, IL3 (1 ng/ml) and blastidin or neomycin (0.5-0.6 mg/ $\mathrm{ml})$ as a selection marker. Cells were grown in triplicate in methylcellulose colony assays. Colonies were counted after 14 days of growth.

Flow cytometry. 32D cells were transfected with GFP-Ras, pcDNA3, pcDNA3-cyclin A1, pCMV-WT1+/- and pCMV$\mathrm{WT} 1^{-/+}$expression vectors with Amaxa kit (Biosystems) protocol (as described in Materials and methods) and incubated for $24 \mathrm{~h}$. For FACS analysis, cells were washed with PBS and $0.1 \%$ BSA, fixed by resuspension in ice-cold $70 \%$ ethanol and incubated on ice for $1 \mathrm{~h}$. After extensive washing, cells were resuspended in PBS containing RNase A and propidium iodide and incubated at room temperature for $30 \mathrm{~min}$ up to $1 \mathrm{~h}$. FACS analyses were performed using FL-1 vs. FL2 channel (GFP vs. PI) in order to get the cell cycle profiles of GFP positive (transfected) cells. Cell cycle distribution was calculated using the ModFitL T V2.0 (PMac) software.

Isoform analysis. A forward primer labelled with fluorescent dye phosphoramidites FAM 5'CAG-ATG-AAC-TTA-GGAGCC-ACC-TTA-A-3' and the unlabeled reverse primer 5'TTG-GCC-ACC-GAC-AGC-TG-3' were used in the PCR. The cDNA from U937 control and U937 cyclin A1 cell line were prepared with M-MLV reverse transcriptase (Promega) following the manufacturer's protocol (described previously). Each PCR mixture contained 50-100 ng of cDNA, 2.5 units of taq polymerase, $1 \mu \mathrm{m}$ of each primer, $10 \mu \mathrm{m}$ each $\mathrm{dNTP}$, $1.5 \mathrm{mM} \mathrm{MgCl}_{2}$, and PCR buffer at a $1 \mathrm{X}$ final concentration. (Applied Biosystems). Thirty cycles of PCR were performed in a DNA-thermal cycler (Master cycler personal, Eppendorf). Initial denaturation at $95^{\circ} \mathrm{C}$ for 4 min was followed by 30-35 cycles of denaturing at $94^{\circ} \mathrm{C}$ for $20 \mathrm{sec}$, annealing at $62^{\circ} \mathrm{C}$ for $20 \mathrm{sec}$, and extension at $72^{\circ} \mathrm{C}$ for $30 \mathrm{sec}$, followed by a terminal extension step at $72^{\circ} \mathrm{C}$ for $10 \mathrm{~min}$. PCR product $(1 \mu \mathrm{l})$ was diluted in $20 \mu \mathrm{l}$ formamide containing $1 \mathrm{IU}$ internal size standard (Gene Scan ROX 1000, Applied Biosystems). Samples were denatured for $2 \mathrm{~min}$ at $90^{\circ} \mathrm{C}$ and run on a 3700 ABI Prism Genetic Analyzer (Applied Biosystems). The data were visualized on a histogram and analyzed by using $\mathrm{ABI}$ Gene Scan Software (Applied Biosystems).

Primers and probes. GAPDH primers and probes include human GAPDH-R, 5'-GAA-GAT-GGT-GAT-GGG-ATTTC-3'; human GAPDH-F, 5'-GAA-GGT-GAA-GGT-CGGAGT-3'; human GAPDH probe, VIC -5'-CAA-GCT-TCCCGT-TCT-CAG-CC-TAMRA-3'. WT1 primers and probes include human WT1 probe, FAM-5-'CCT-ACC-CAG-CCTCGA-TTT-TTT-CAT-ATT-GCA-A-TAMRA-3'; human WT1-F, 5'-GAG-AAA-TCC-TCA-CTG-CCC-TGC-3'; human WT1-R, 5'-CGG-CCT-CGA-AGG-TGC-AT-3'; mouse WT1 probe, FAM-5'CGC-CCT-ACA-GCA-GTG-ACAATT-TAT-ACC-AAA-TG-TAMRA-3'; mouse WT1-F, 5'CCA-GGC-CCT-GCT-CCT-GA-3'; mouse WT1-R, 5'-GTCATG-CAT-TCA-AGC-TGG-GA-3'.

\section{Results}

Identification of target genes by microarray analysis in cyclin A1 overexpressing U937 cells. U937 cells overexpressing cyclin A1 after retroviral transduction were analyzed for differences in mRNA expression by high density oligonucleotide arrays. Differentially expressed genes were determined as described in Materials and methods. With this stringent criteria, 35 genes were regarded as differentially expressed with 21 being induced and 14 being repressed upon cyclin A1 induction (Fig. 1). Out of these genes the Wilms tumor gene (WT1) was selected for further analysis since this gene is known to be involved in growth regulation and tumor pathogenesis.

Expression of WT1 is reduced in cyclin Al-overexpressing U937 cells. Quantitative RT-PCR was performed with U937 control and cyclin A1 overexpressing cells cultured in the presence of $10 \%$ FCS. The expression of WT1 in cyclin A1 overexpressing U937 cells was reduced by $70 \%$ as compared to expression in U937 control cells (Fig. 2). The reduction of WT1 expression in cyclin A1-overexpressing U937 cells was confirmed on the protein level by Western blot analysis (Fig. 3). The two bands detected at 54-52 kDa and $42 \mathrm{kDa}$ appeared to be different isoforms of WT1, as previously reported (10-12).

WT1 expression in cyclin A1/- mice tissues. Bone marrow of cyclin $\mathrm{A}^{-/}$mice expressed higher levels of WT1 mRNA 


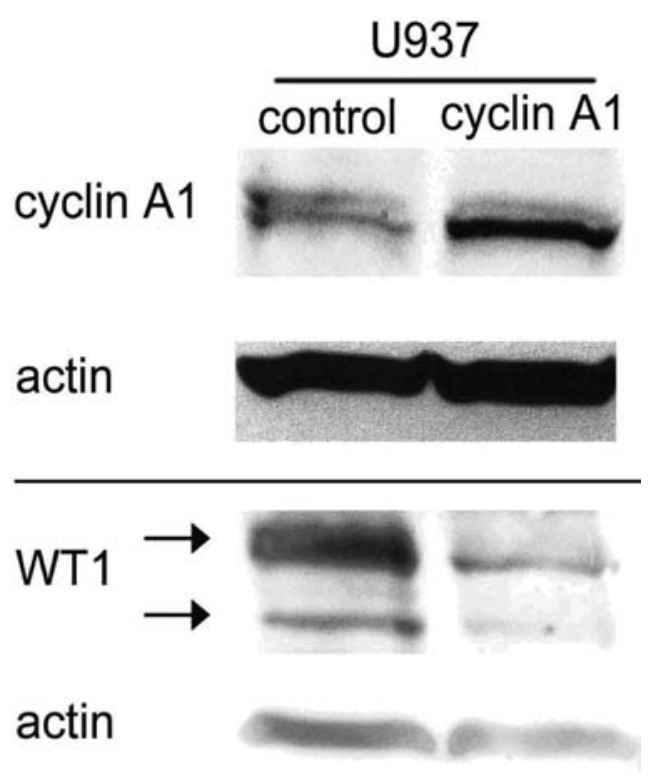

Figure 3. WT1 is downregulated at the protein level in U937 cells overexpressing cyclin A1. The level of cyclin A1 protein was also shown in this immunblot for comparison. The blots were probed with antibodies for cyclin A1 and WT1 respectively and subsequently for actin. The WT1 antibody detected bands at $54-52 \mathrm{kDa}$ and $42 \mathrm{kDa}$ and the actin antibody at $42 \mathrm{kDa}$.

(Fig. 4A). Moreover, in testis, liver, and ovary the expression of WT1 was also increased in the absence of cyclin A1 (Fig. 4B). This is in accordance with the findings in the leukemia cell lines. However, in lung tissue WT1 expression was decreased in cyclin $\mathrm{A} 1^{-/-}$mice (Fig. 4B).

Expression of WT1 isoforms in U937 cyclin A1 overexpressing and control cells. The WT1 primary transcript has been described to undergo two alternatives splicing events, giving rise to four isoforms of mRNA (13). Alternative splicing of exon 5 removes 17 amino acids from the middle of the protein. The other alternate splicing event (KTS) removes 3 amino acids between the third and fourth zinc finger domain (see Fig. 5). The 4 isoforms are produced in a constant ratio that is conserved throughout in different species suggesting that they have non-overlapping functions. It was also reported that an imbalance in WT1 isoforms can lead to tumor development $(14,15)$.

In U937 control cells only the WT1\% isoform was expressed (Fig. 6, upper histogram). In contrast, in U937 cells overexpressing cyclin A1 all isoforms were present (Fig. 6, lower histogram) with the following relative expression values, as determined by histogram: WT1 $1^{-/}$(482 bp, $\left.12 \%\right)$; $\mathrm{WT}^{-/+}$(489 bp, 24\%); WT1 ${ }^{+/}(528 \mathrm{bp}, 26 \%)$; WT1 ${ }^{+/+}$(535 bp, $36 \%)$.

WT1 isoforms inhibit colony growth. When transfected into either U937 control cells, each $\mathrm{WT}^{+/-}$, WT1 ${ }^{-/+}, \mathrm{WT}^{+/+}$and $\mathrm{WT}{ }^{-/}$isoform, reduced the colony formation by $\sim 50 \%$ compared to a transfection with the empty vector (Fig. 7). This reduction was not affected by the overexpression of cyclin A1 in cyclin A1 overexpressing U937 cells (Fig. 7). Cyclin A1 has been reported to enhance cell cycle progression and proliferation in leukemic cells. Suppression of the growth
A

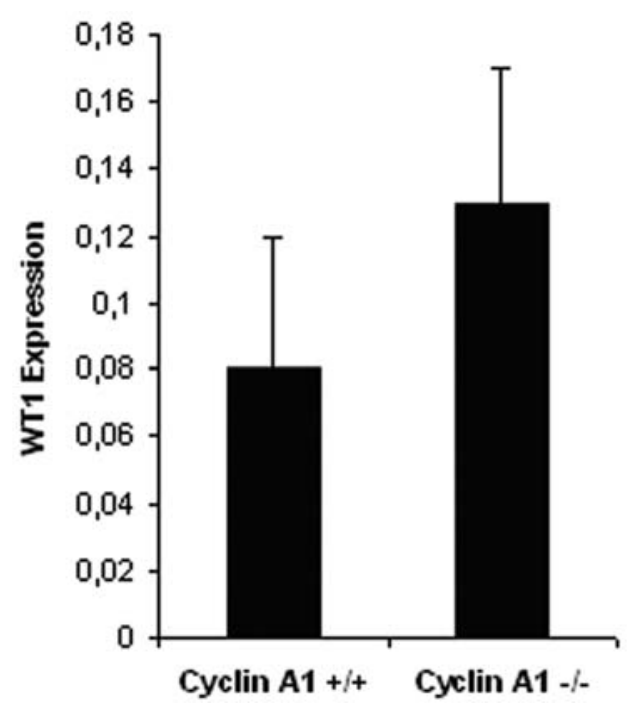

B

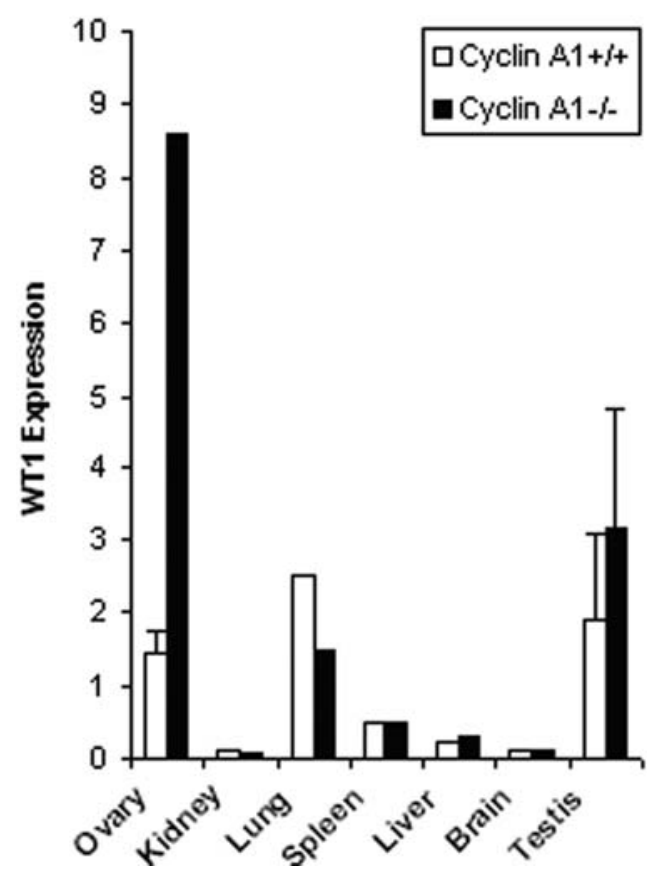

Figure 4. mRNA expression levels of WT1 in bone marrow (A) and different organs (B) of cyclin $\mathrm{A} 1^{+/+}$and cyclin $\mathrm{A} 1^{-/-}$mice. Expression levels of the WT1 were determined by quantitative RT-PCR. The expression level of WT1 was standardized using expression of GAPDH as a standard. Expression levels were determined in triplicates and are shown as the mean + SE

inhibitory WT1 would fit into the picture of the cell cycle enhancing features of overexpressed cyclin A1.

WT1 ${ }^{+/-}$isoform induces G1 arrest. Cyclin A1 is known to be involved in the G1/S transition in cell cycle progression. Therefore, we analyzed whether expression of $\mathrm{WT} 1^{-/+}$or $\mathrm{WT} 1^{+/-}$isoforms in the presence or absence of cyclin A1 would alter cell cycle progression in $32 \mathrm{D}$ cells. 


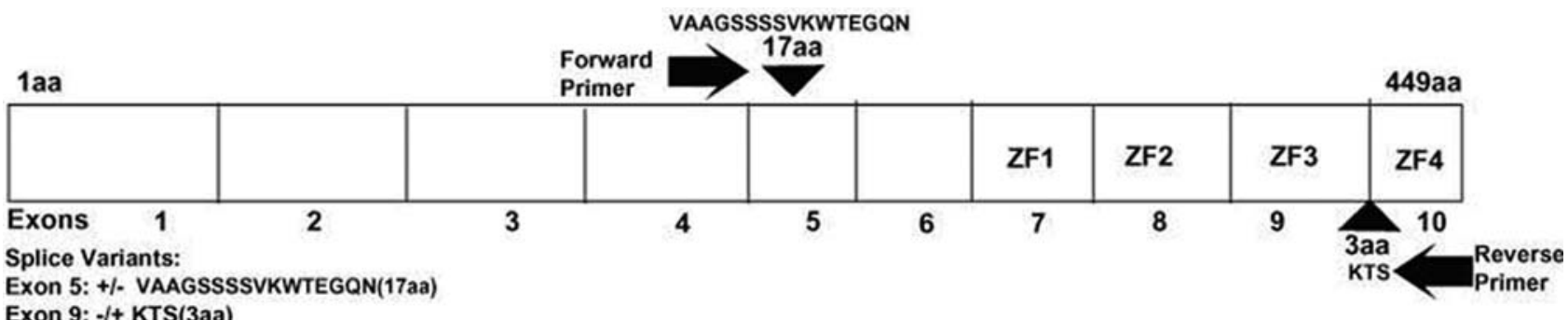

Figure 5. Schematic presentation of alternative WT1 splicing and the position of primers. The insertion and exclusion of the two splice inserts (17aa and KTS) generates the four isoforms (WT1 $1^{-/}$, WT1 ${ }^{+/+}, \mathrm{WT}^{+/-}$and $\mathrm{WT} 1^{-/+}$). The forward primer (upstream of the17aa) was labelled with $\mathrm{FAM}(\mathrm{Flourescent}$ dye phosphoramidites), the reverse primer (downstream of the KTS region) remained unlabelled.
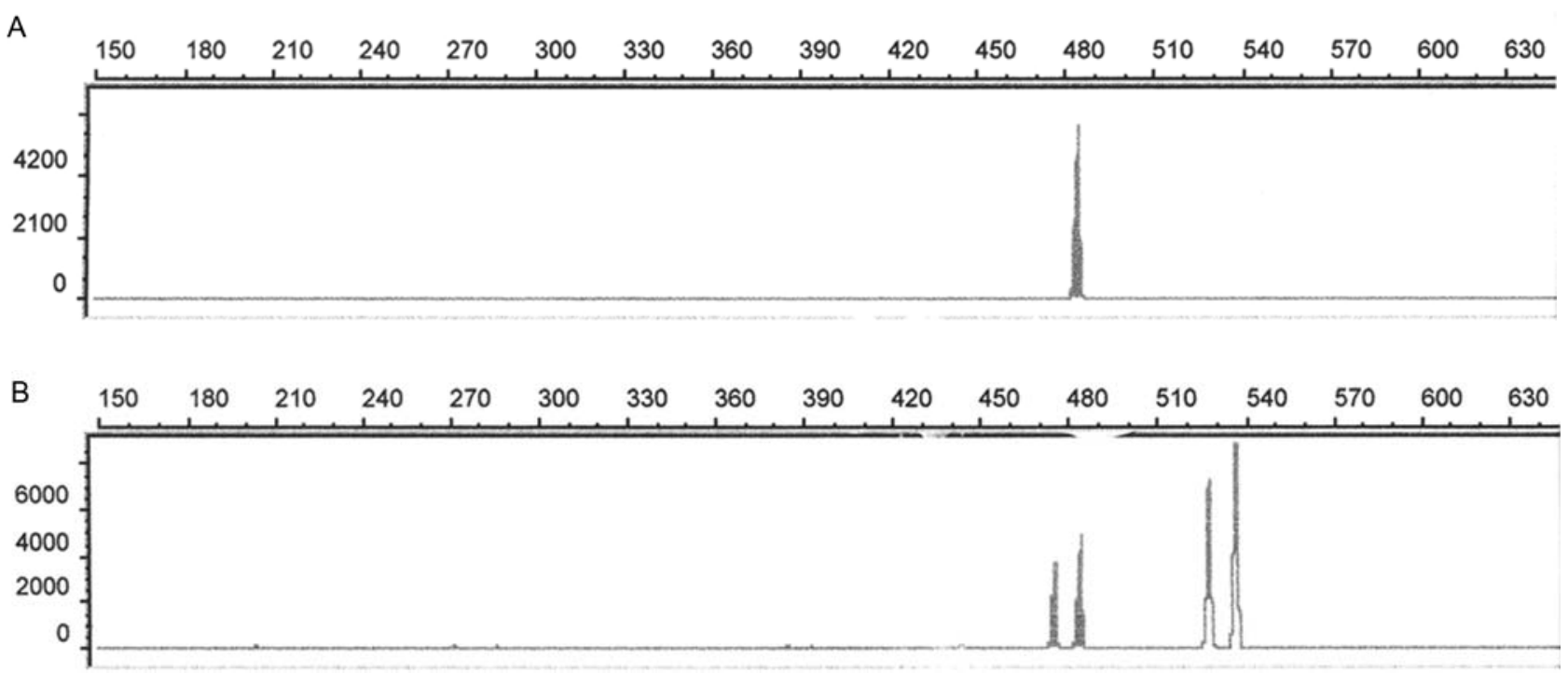

Figure 6. WT WT $^{-/}$isoform was predominantly expressed in U937 control. The PCR product was run along with internal size standard (Gene Scan Rox 1000) on a 3700 ABI Prism genetic analyzer. The data were visualized using ABI Gene Scan software (Applied Biosystems).

Table I. Cell cycle distribution of WT1 in 32D cells.

\begin{tabular}{lccc}
\hline \multirow{2}{*}{ Transfected constructs } & \multicolumn{3}{c}{ Cell cycle distribution (\%) } \\
\cline { 2 - 4 } & $\mathrm{G} 1$ & $\mathrm{~S}$ & $\mathrm{G} 2 / \mathrm{M}$ \\
\hline pcDNA3 & $55.68(1.9)$ & $28.73(0.4)$ & $14.59(3.7)$ \\
Cyclin A1 & $52.95(0.1)$ & $31.53(0.7)$ & $14.06(2.9)$ \\
$\mathrm{WT1}^{+/-}$ & $53.08(0.1)$ & $31.43(2.2)$ & $13.49(4.9)$ \\
$\mathrm{WT1}^{-/+}$ & $61.25(0.4)$ & $22.35(1.9)$ & $15.59(0.6)$ \\
Cyclin A1 and WT1 $^{+/-}$ & $48.30(1.8)$ & $34.79(6.0)$ & $15.41(6.2)$ \\
Cyclin A1 and WT1 $^{-/+}$ & $55.77(7.4)$ & $27.89(4.1)$ & $15.84(4.0)$ \\
\hline
\end{tabular}

pcDNA3, $\mathrm{WT}^{+/-}$, $\mathrm{WT}^{-/+}$were transfected with or without cyclin A1 in 32D cells. Cell cycle analysis was performed using propidium iodide staining. Figures indicate the percentage of cells in the different phases of the cell cycle, and the ratio of cells in G1 to cells in S and G2/M phase. Numbers in parentheses represent the $+\mathrm{SE}$.

The expression of $\mathrm{WT}^{-/+}$led to a cell cycle arrest. This block occurred in $\mathrm{G} 1$ to $\mathrm{S}$ phase progression in 32D cells (Fig. 8). WT1 $1^{-1+}$ induced G1 cell cycle arrest. When cyclin A1 was co-transfected with the WT1 isoforms, cyclin A1 abrogated the $\mathrm{WT} 1^{+/}$-induced cell cycle arrest (Fig. 8). The percentage of cells distributed in the different phases of cell cycle is shown in Table I.

\section{Discussion}

In this study, we identified genes with a differential expression upon overexpression of cyclin A1. None of these genes was previously known to be associated with cyclin A1. The repression of the WT1 gene was verified both on the mRNA and on the protein level. The WT1 gene is a tumor suppressor gene which encodes a member of the Cys2-His2 zinc finger family of transcription factors. Some data suggest that WT1 plays a role in hematopoietic differentiation: Expression of the WT1 gene has been detected in several myeloid cell lines and $\mathrm{CD} 34^{+}$hematopoietic precursors (16) and its expression disappears during differentiation $(17,18)$. In addition, WT1 overexpression was found to interfere with the induced differentiation in these cells $(19,20)$ and leukemic cells treated with wt1 siRNA showed a loss in proliferation and increase in apoptosis (21).

A possible role of WT1 in AML is supported by the finding that high levels of WT1 expression have adverse prognostic significance in AML (22). Heterozygous WT1 mutations are 


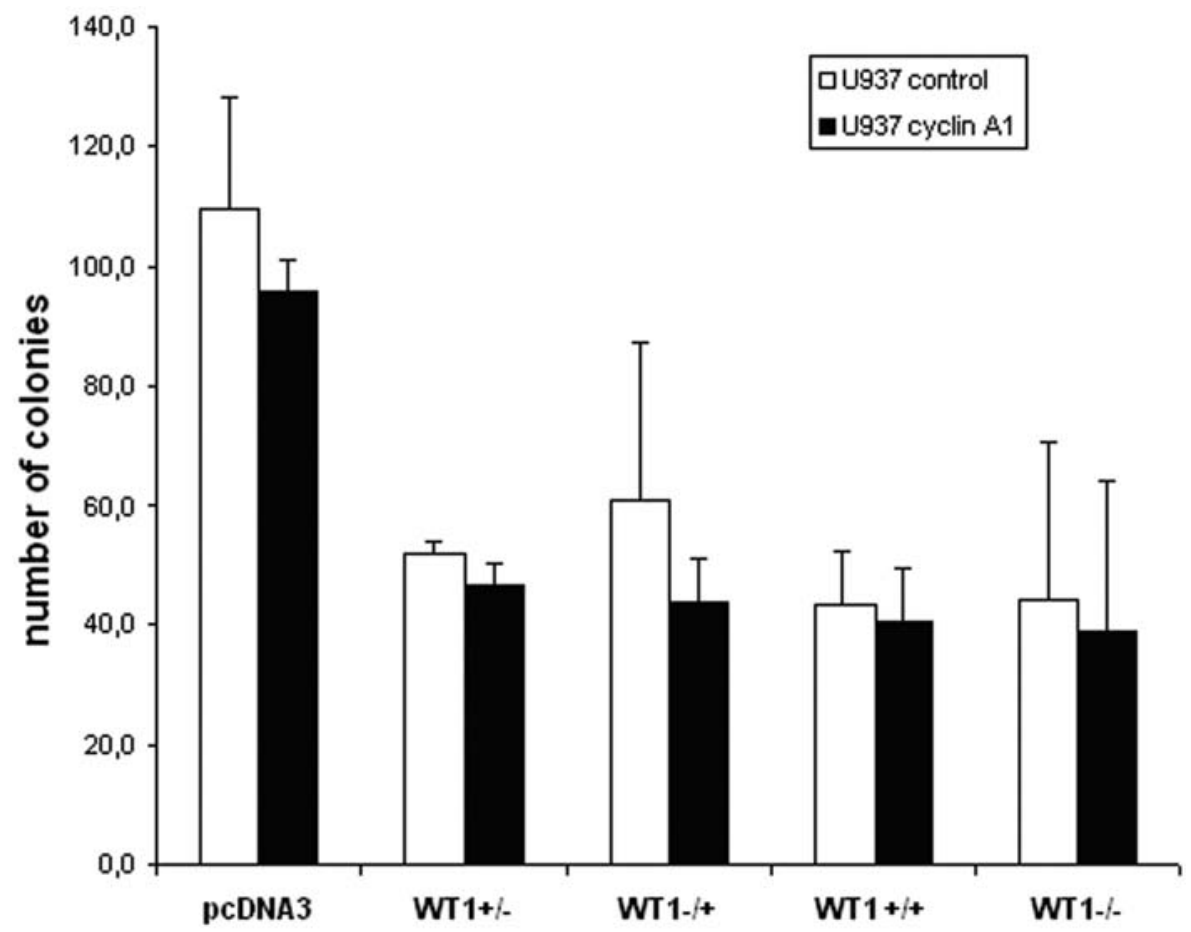

Figure 7. Colony assay in U937 control and overexpressing cyclin A1 with different WT1 isoforms. U937 cells were transfected with pcDNA3, WT1 ${ }^{-1+}$, $\mathrm{WT} 1^{+/-} \mathrm{WT} 1^{+/+}$and $\mathrm{WT} 1^{-/}$. The following day, cells were seeded in triplicate in methylcellulose colony assays in the presence of neomycin as a selection marker. Colonies were counted after 14 days. The result was observed in at least three independent experiments and is shown as the mean + SE.

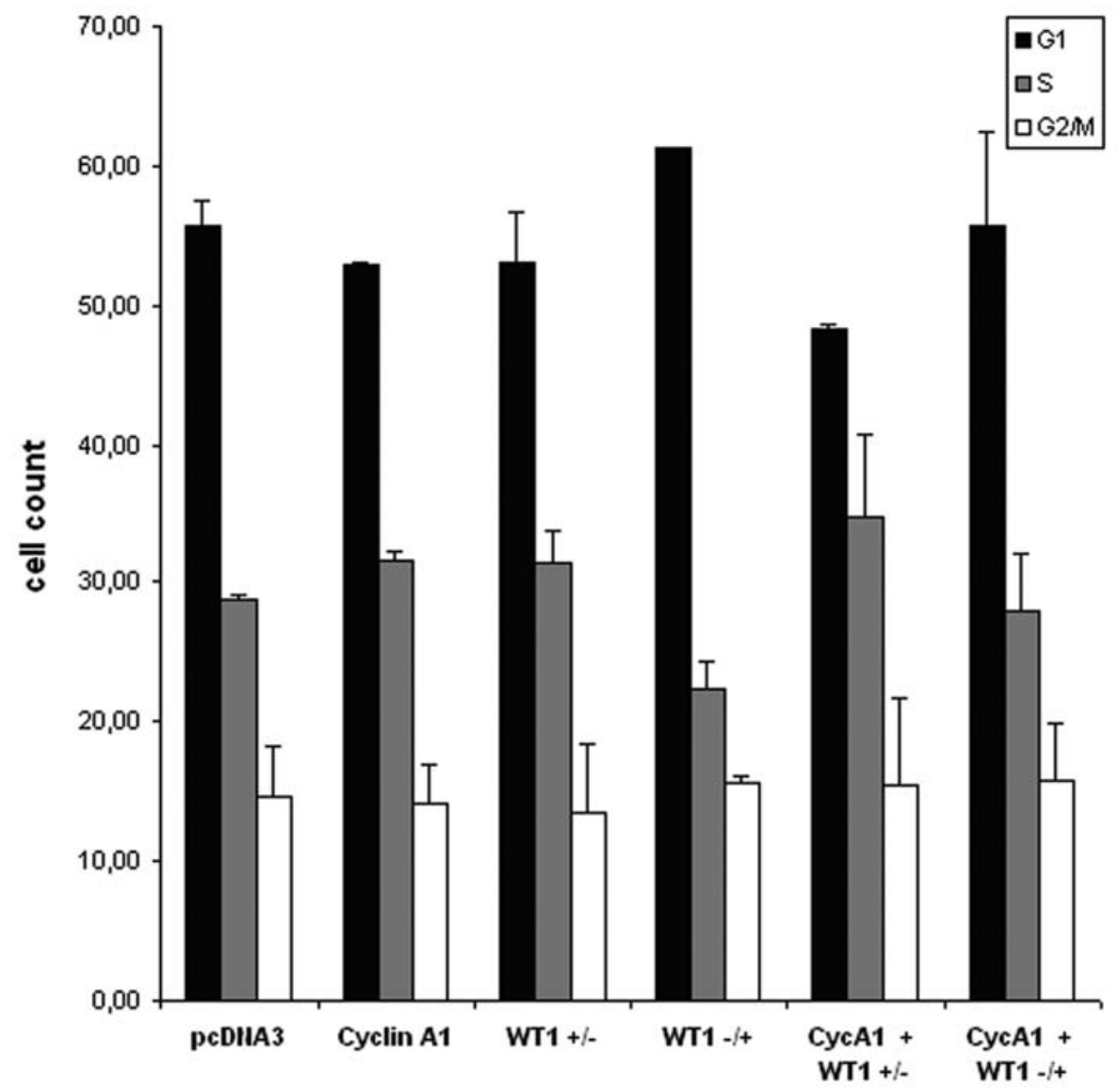

Figure 8. Effects of WT1 isoforms on cell cycle regulation by FACS. Empty vector, cyclin A1, WT1 $1^{+/}$, WT1 $1^{-/+}$were transfected with and without cyclin A1 in 32D cells. After $24 \mathrm{~h}$ the cells were stained with propidium iodide, sorted by FACS, and cell cycle distribution was calculated using the ModFitL T V2.0 (PMac) software. The number of cells transfected in different phases was compared to the cells transfected with control vector. The result presented was the mean $+\mathrm{SE}$ of three independent experiments. 
found in $\sim 15 \%$ of AML cases and are associated with poor response to chemotherapy (23).

In addition to the verification of repression of WT1 expression in this cyclin A1-overexpressing in vitro model, additional data provide evidence that cyclin A1 at physiological doses regulate WT1 levels. WT1 expression was reduced in the bone marrow of cyclin $\mathrm{A} 1^{-/}$mice. This reduction was also observed in testis, liver, and ovary tissue, suggesting that the same control of WT1 expression by cyclin A1 is functional in these tissues. However, this regulation is restricted to high cyclin A1 expressing tissues, since in lung tissue an opposite effect on the expression of WT1 was observed upon deletion of cyclin A1. A variety of transcriptional regulators, such as $\mathrm{E} 2 \mathrm{~F}$ proteins and $\mathrm{CBP}$, form stable complexes with cyclin A1/CDK complexes (24). Hypothetically, the binding of transcriptional regulators to cyclin A1/CDK-complexes is tissue-specific, thus exerting a differential transcriptional activity by cyclin A1 in different tissues. However, this is highly speculative and has to be investigated by further studies.

In mammals, exons 5 and 9 of WT1 are alternatively spliced $(13,25)$. Splice variant 1 results in the insertion of 17 amino acids upstream of the zinc finger domain and enhances the transcriptional activity of protein (26). Splice variant 2 occurs within the zinc finger domain, inserting three amino acids (Lys-Thr-Ser; KTS) between the third and the fourth zinc finger. This splice variant alters the DNA binding specificity of the protein $(27,28)$. Alternative splicing of WT1 gives rise to 4 different splice isoforms (25), termed $\mathrm{WT} 1^{+/+}$(both splice variants 1 and 2 are present), WT1 $1^{+/-}$ (only splice variant 1 is present), $\mathrm{WT}^{-/+}$(only splice variant 2 is present), and $\mathrm{WT}^{-/-}$(neither splice variant present). These 4 isoforms display molecular masses in the range of 52-54 kDa (29).

The combined expression of all splice variants might be essential for normal functioning. The different isoforms were investigated using capillary electropherosis of fluorescent labelled PCR products. Only the $\mathrm{WT}^{-/-}$isoform was found in the U937 control samples. This observation for the first time identified a cell line with predominant expression of a sole WT1 isoform, compared to all other published results with respect to isoform distribution. In contrast, overexpression of cyclin A1 in these cells led to the expression of all isoforms at different ratios albeit at much lower overall levels. A mutation interfering with the ratio of WT1 (+KTS) and WT1 (-KTS) protein reportedly leads to the Frazier syndrome (30). Furthermore, the $\mathrm{WT}^{+/+}(+17 \mathrm{aa})$ and $\mathrm{WT} 1^{-/+}(-17 \mathrm{aa})$ ratio is also important, and absence of $\mathrm{WT}^{-/}$showed poor postnatal survival and glomerular abnormalities in mice $(31,32)$.

In concordance with previous results, the transfection of WT isoforms into myeloid cell showed a pronounced reduction in colony growth (33). In previous studies it was reported that WT1 (-KTS) and WT1 (+KTS) differently affect the growth suppression of primary hematopoietic cells $(33,34)$. However, in this study the growth reduction by WT1 was equal in every isoform. In addition, the growth inhibition by WT1 isoforms was not affected by the overexpression of cyclin A1. WT1 $1^{-/+}$ was shown to induce G1 arrest in 32D cells, which further suggest that this isoform was involved in different functions of myeloid cells. Different reports indicate that WT1 has relevance for the induction of growth arrest and apoptosis (35-37). Overexpression of WT1 blocked the G1-S transition of NIH3t3 and induced apoptosis in F9 embryonal carcinoma cells and in an osteosarcoma cell line $(36,38,39)$. The M1 murine myeloblastic cell line expressing no endogenous WT1 reacts very differently to ectopic expression. Constitutive expression of the WT1 (+KTS) form induces monocytic differentiation independent of external stimuli. In contrast, M1 cells stably expressing the WT1 (-KTS) isoform could not be established due to the induction of G1 arrest and/or apoptosis $(11,35)$. These findings also indicate that the effects of WT1 isoforms are different with respect to the various cell backgrounds. In the current study, WT1 (+KTS) was involved in $\mathrm{G} 1$ arrest, which was contradictory to previous results. A possible explanation for this could be the specific background of cells. In a previous study, it was observed that overexpression of cyclin E/cdk2 or cyclin D1/cdk4 induced cell cycle progression into $\mathrm{S}$ phase, which is blocked by WT1 (38). In this study, the co-transfection of cyclin A1 released the G1 arrest. In conclusion, cyclin A1 might interact with WT1 directly or indirectly during the cell cycle.

Collectively, this study identified several potential target genes of cyclin A1 and identified WT1 as a repressed target gene of cyclin A1. Furthermore, this study suggests that the suppression of WT1 in cyclin A1-overexpressing leukemias might play a role in the growth and suppression of apoptosis in these leukemic cells.

\section{Acknowledgements}

This study was supported by the Deutsche Forschungsgemeinschaft, the Deutsche Krebshilfe and the IZKF at the University of Münster.

\section{References}

1. Yang R, Morosetti R and Koeffler HP: Characterization of a second human cyclin A that is highly expressed in testis and in several leukemic cell lines. Cancer Res 57: 913-920, 1997.

2. Sweeney C, Murphy M, Kubelka M, Ravnik SE, Hawkins CF, Wolgemuth DJ and Carrington M: A distinct cyclin A is expressed in germ cells in the mouse. Development 122: 53-64, 1996.

3. Yang R, Muller C, Huynh V, Fung YK, Yee AS and Koeffler HP: Functions of cyclin A1 in the cell cycle and its interactions with transcription factor $\mathrm{E} 2 \mathrm{~F}-1$ and the $\mathrm{Rb}$ family of proteins. Mol Cell Biol 19: 2400-2407, 1999.

4. Muller-Tidow C, Wang W, Idos GE, et al: Cyclin A1 directly interacts with B-myb and cyclin A1/cdk2 phosphorylate B-myb at functionally important serine and threonine residues: tissuespecific regulation of B-myb function. Blood 97: 2091-2097, 2001.

5. Liu D, Matzuk MM, Sung WK, Guo Q, Wang $P$ and Wolgemuth DJ: Cyclin A1 is required for meiosis in the male mouse. Nat Genet 20: 377-380, 1998.

6. Yang R, Nakamaki T, Lubbert M, et al: Cyclin A1 expression in leukemia and normal hematopoietic cells. Blood 93: 2067-2074, 1999.

7. Liao C, Wang XY, Wei HQ, Li SQ, Merghoub T, Pandolfi PP and Wolgemuth DJ: Altered myelopoiesis and the development of acute myeloid leukemia in transgenic mice overexpressing cyclin A1. Proc Natl Acad Sci USA 98: 6853-6858, 2001.

8. Tusher VG, Tibshirani $\mathrm{R}$ and Chu G: Significance analysis of microarrays applied to the ionizing radiation response. Proc Natl Acad Sci USA 98: 5116-5121, 2001.

9. Muller-Tidow C, Bornemann C, Diederichs S, et al: Analyses of the genomic methylation status of the human cyclin A1 promoter by a novel real-time PCR-based methodology. FEBS Lett 490: 75-78, 2001. 
10. Inoue K, Tamaki H, Ogawa H, et al: Wilms' tumor gene (WT1) competes with differentiation-inducing signal in hematopoietic progenitor cells. Blood 91: 2969-2976, 1998.

11. Smith SI, Weil D, Johnson GR, Boyd AW and Li CL: Expression of the Wilms' tumor suppressor gene, WT1, is upregulated by leukemia inhibitory factor and induces monocytic differentiation in M1 leukemic cells. Blood 91: 764-773, 1998.

12. Smith SI, Down M, Boyd AW and Li CL: Expression of the Wilms' tumor suppressor gene, WT1, reduces the tumorigenicity of the leukemic cell line M1 in C.B-17 scid/scid mice. Cancer Res 60: 808-814, 2000.

13. Haber DA, Sohn RL, Buckler AJ, Pelletier J, Call KM and Housman DE: Alternative splicing and genomic structure of the Wilms tumor gene WT1. Proc Natl Acad Sci USA 88: 9618-9622, 1991.

14. Klamt B, Koziell A, Poulat F, Wieacker P, Scambler P, Berta P and Gessler M: Frasier syndrome is caused by defective alternative splicing of WT1 leading to an altered ratio of WT1 +/-KTS splice isoforms. Hum Mol Genet 7: 709-714, 1998.

15. Baudry D, Faussillon M, Cabanis MO, et al: Changes in WT1 splicing are associated with a specific gene expression profile in Wilms' tumour. Oncogene 21: 5566-5573, 2002.

16. Scharnhorst V, van der Eb AJ and Jochemsen AG: WT1 proteins: functions in growth and differentiation. Gene 273: 141-161, 2001 .

17. Fraizer GC, Patmasiriwat P, Zhang X and Saunders GF: Expression of the tumor suppressor gene WT1 in both human and mouse bone marrow. Blood 86: 4704-4706, 1995.

18. Miwa H, Beran M and Saunders GF: Expression of the Wilms' tumor gene (WT1) in human leukemias. Leukemia 6: 405-409, 1992.

19. Sekiya M, Adachi M, Hinoda Y, Imai K and Yachi A: Downregulation of Wilms' tumor gene (wt1) during myelomonocytic differentiation in HL60 cells. Blood 83: 1876-1882, 1994.

20. Svedberg H, Chylicki K, Baldetorp B, Rauscher FJ III and Gullberg U: Constitutive expression of the Wilms' tumor gene (WT1) in the leukemic cell line U937 blocks parts of the differentiation program. Oncogene 16: 925-932, 1998.

21. Glienke W, Maute L, Koehl U, Esser R, Milz E and Bergmann L: Effective treatment of leukemic cell lines with wt1 siRNA. Leukemia 21: 2164-2170, 2007.

22. Rosenfeld C, Cheever MA and Gaiger A: WT1 in acute leukemia, chronic myelogenous leukemia and myelodysplastic syndrome: therapeutic potential of WT1 targeted therapies. Leukemia 17: $1301-1312,2003$.

23. King-Underwood L and Pritchard-Jones K: Wilms' tumor (WT1) gene mutations occur mainly in acute myeloid leukemia and may confer drug resistance. Blood 91: 2961-2968, 1998.

24. Kim TY and Kaelin WG Jr: Differential control of transcription by DNA-bound cyclins. Mol Biol Cell 12: 2207-2217, 2001.

25. Gessler M, Konig A and Bruns GA: The genomic organization and expression of the WT1 gene. Genomics 12: 807-813, 1992.

26. Rupprecht HD, Drummond IA, Madden SL, Rauscher FJ III and Sukhatme VP: The Wilms' tumor suppressor gene WT1 is negatively autoregulated. J Biol Chem 269: 6198-6206, 1994.
27. Rauscher FJ III, Morris JF, Tournay OE, Cook DM and Curran T: Binding of the Wilms' tumor locus zinc finger protein to the EGR-1 consensus sequence. Science 250: 1259-1262, 1990.

28. Bickmore WA, Oghene K, Little MH, van Heyningen V, Seawright A and Hastie ND: Modulation of DNA binding specificity by alternative splicing of the Wilms tumor wt1 gene transcript. Science 257: 235-237, 1992.

29. Morris JF, Madden SL, Tournay OE, Cook DM, Sukhatme VP and Rauscher FJ III: Characterization of the zinc finger protein encoded by the WT1 Wilms' tumor locus. Oncogene 6: 2339-2348, 1991.

30. Kohsaka T, Tagawa M, Takekoshi Y, Yanagisawa H, Tadokoro K and Yamada M: Exon 9 mutations in the WT1 gene, without influencing KTS splice isoforms, are also responsible for Frasier syndrome. Hum Mutat 14: 466-470, 1999.

31. Natoli TA, Liu J, Eremina V, et al: A mutant form of the Wilms' tumor suppressor gene WT1 observed in Denys-Drash syndrome interferes with glomerular capillary development. J Am Soc Nephrol 13: 2058-2067, 2002.

32. Natoli TA, McDonald A, Alberta JA, Taglienti ME, Housman DE and Kreidberg JA: A mammal-specific exon of WT1 is not required for development or fertility. Mol Cell Biol 22: 4433-4438, 2002.

33. Svedberg H, Richter J and Gullberg U: Forced expression of the Wilms tumor 1 (WT1) gene inhibits proliferation of human hematopoietic CD34(+) progenitor cells. Leukemia 15: 1914-1922, 2001.

34. Ellisen LW, Carlesso N, Cheng T, Scadden DT and Haber DA: The Wilms tumor suppressor WT1 directs stage-specific quiescence and differentiation of human hematopoietic progenitor cells. EMBO J 20: 1897-1909, 2001.

35. Murata Y, Kudoh T, Sugiyama H, Toyoshima K and Akiyama T: The Wilms tumor suppressor gene WT1 induces G1 arrest and apoptosis in myeloblastic leukemia M1 cells. FEBS Lett 409: 41-45, 1997

36. Englert C, Hou X, Maheswaran S, et al: WT1 suppresses synthesis of the epidermal growth factor receptor and induces apoptosis. EMBO J 14: 4662-4675, 1995.

37. Menke AL, Shvarts A, Riteco N, van Ham RC, van der Eb AJ and Jochemsen AG: Wilms' tumor 1-KTS isoforms induce p53-independent apoptosis that can be partially rescued by expression of the epidermal growth factor receptor or the insulin receptor. Cancer Res 57: 1353-1363, 1997.

38. Kudoh T, Ishidate T, Moriyama M, Toyoshima K and Akiyama T: G1 phase arrest induced by Wilms tumor protein WT1 is abrogated by cyclin/CDK complexes. Proc Natl Acad Sci USA 92: 4517-4521, 1995.

39. Kudoh T, Ishidate T, Nakamura T, Toyoshima K and Akiyama T: Constitutive expression of the Wilms tumor suppressor gene WT1 in F9 embryonal carcinoma cells induces apoptotic cell death in response to retinoic acid. Oncogene 13: 1431-1439, 1996. 